\title{
SYNERGIC EFFECT OF TWO INORGANIC FILLERS ON THE MECHANICAL AND THERMAL PROPERTIES OF HYBRID POLYPROPYLENE COMPOSITES
}

\author{
HÉCTOR AGUILAR', MEHRDAD YAZDANI-PEDRAM ${ }^{*}$, PATRICIO TORO', \\ RAÚL QUIJADA², MIGUEL ÁNGEL, LÓPEZ-MANCHADO \\ ${ }^{1}$ Facultad de Ciencias Químicas y Farmacéuticas, Universidad de Chile, S. Livingstone 1007, Independencia, Santiago, Chile. \\ ${ }^{2}$ Facultad de Ciencias Físicas y Matemáticas, Universidad de Chile, Santiago, Chile. \\ ${ }^{3}$ Instituto de Ciencia y Tecnología de Polímeros (ICTP-CSIC), Juan de la Cierva, 3 28006-Madrid, Spain.
}

\begin{abstract}
Inorganic fillers such as $\mathrm{CaCO}_{3}$ and clays are widely used as fillers to improve the mechanical and physical properties of polypropylene (PP). With the aim of improving simultaneously the stiffness and yield stress of $\mathrm{PP}$, hybrid nanocomposites comprising $\mathrm{PP} / \mathrm{CaCO}_{3} /$ clay (montmorillonite) were prepared and their thermal and mechanical properties were investigated and compared with those of $\mathrm{PP} / \mathrm{CaCO}_{3}$ and $\mathrm{PP} /$ clay composites. Morphological characterizations of the composites were performed by SEM and XRD analyses. The results showed exfoliated clay in the hybrid composite with a much higher degree than in PP/ clay composite. Increase in modulus and yield stress and better thermal stability was attained for hybrid composites as a result of the clay exfoliation. The toughening effect of two different types of $\mathrm{CaCO}_{3}$ particles was also observed in hybrid composites, where an effective enhancement of the mechanical and thermal properties were achieved depending on the origin, specific area, particle and pore size of the $\mathrm{CaCO}_{3}$ used.
\end{abstract}

Keywords: Inorganic fillers, polypropylene, hybrid nanocomposites, mechanical properties, thermal properties

\section{INTRODUCTION}

Polypropylene (PP) is one of the most widely used polyolefin. This is mainly due to a good balance of its physical and mechanical properties as well as its low cost. In order to expand the scope of PP application, many works have carried out to modify PP by chemical or physical methods. Chemical methods include copolymerization, grafting and crosslinking, which change the molecular structure of PP, while physical methods include blending or by incorporation of reinforcing fillers to obtain the so called PP composites. The incorporation of fibers in PP matrix is an effective way to improve the mechanical and thermal properties of this polymer. Glass fiber reinforced PP composites have excellent mechanical properties and heat resistance [1], but there is a large wear on the equipment during the processing and the material is difficult to recycle [2]. A common problem in reinforced PP composites is the poor compatibility and adhesion between the filler and PP matrix. This could be overcome by using coupling agents $[3,4]$. Besides fibers, silica, $\mathrm{CaCO}_{3}$, clay and carbon nanotubes have been widely used to reinforce PP [5-10].

To provide PP composites with an optimum balance of toughness and stiffness, recently works have been focused on fabricating multicomponent or hybrid PP composites containing fiber or elastomer and inorganic particles [1113], where traditional fabrication process have been employed [14]. However, the performance of hybrid composites was even worse than the PP composites containing a single filler because the properties of composites not only depends on the components, but also depends on the phase structure and phase size [15]. The relationship between component, structure and the property of the materials, so far, were not completely understood.

PP is highly crystalline, favoring the generation of large spherulites. Cracks occur easily on the spherulite interface defects and grain boundaries. The crack expands and extends rapidly under impact load, followed by a sharp fracture of material. Therefore, neat PP has poor impact performance and low modulus. The most common method used to obtain clay/polymer composites is the direct polymer melt intercalation, but the low polarity of PP intricate a homogenous dispersion of the filler, therefore, the matrix requires prior functionalization with polar compounds that allow a better interaction of the polymeric matrix and modified clay. For this purpose, the clay is modified with organic compounds and PP is functionalized with a polar compound such as maleic anhydride.

This work was aimed to the study of the synergic effect of two different inorganic fillers on the mechanical and thermal properties of PP/clay nanocomposites. This study included the preparation and characterization of $\mathrm{PP} /$ clay nanocomposites and $\mathrm{PP} / \mathrm{clay} / \mathrm{CaCo} 3$ hybrid composites containing either a commercial $\mathrm{CaCo}_{3}$ (CC) or a biomineralized $\mathrm{CaCo}_{3}$ (MCC) obtained from eggshells in our laboratory. All composites were prepared by melt compounding and the relationship between the composite components, structures and properties and the reinforcement mechanism on the mechanical performance of composites were studied in detail based on X-ray diffraction analysis (XRD), tensile mechanical measurements and thermal analysis.

\section{EXPERIMENTAL}

\section{Materials}

The clay used as nanofiller was a sodium montmorillonite (MMT) with cation exchange capacity of $80 \mathrm{meq} / 100 \mathrm{~g}$, interlayer distance of $1.3 \mathrm{~nm}$ and specific surface area of $41.0 \mathrm{~m} / \mathrm{g}$. Distearyl dimethyl ammonium chloride (DSQ), a quaternary ammonium salt from Clariant GMBH was used to obtain an organically modified montmorillonite (oMMT). Polypropylene used as matrix was a homopolymer from Petroquim S. A., Chile, with melt flow index (MFI) of $13 \mathrm{~g} / \mathrm{min}\left(230^{\circ} \mathrm{C} ; 2.16 \mathrm{Kg}\right)$. The compatibilizer used was Polybond 3002 from Uniroyal Chemicals USA, a polypropylene grafted with 0.2 wt. \% maleic anhydride (PP-g-MA). Calcium carbonate (GC) was Microcarb 95 from Reverté industry with specific surface area of $9.1 \mathrm{~m} / \mathrm{g}$, particle size of $0.7 \mu \mathrm{m}$ and pore size of $124 \AA$. Biomineralized calcium carbonate (MCC) was used as alternative filler instead of mineral CC. It was obtained from eggshells in our laboratory [16] and had a specific surface area of $18 \mathrm{~m} / \mathrm{g}$, particle size of 8.4 $\mu \mathrm{m}$ and pore size of $114 \AA$.

\section{Clay modification by DSQ intercalation}

MMT was modified by intercalation with DSQ. A solution of DSQ was added to the aqueous clay suspension at $\mathrm{pH} 3$ and the mixture was stirred for 2 hours at $80^{\circ} \mathrm{C}$. The organically modified MMT (oMMT) was separated by centrifugation at $5000 \mathrm{rpm}$ during $5 \mathrm{~min}$ and then dried at $100{ }^{\circ} \mathrm{C}$ for 12 hours. The organophilization reaction was characterized by X-ray diffraction (XRD) and Fourier transform infrared (FTIR) spectroscopy. The XRD patterns were recorded using a Siemens D5000 Powder X-ray diffractometer with $\mathrm{Cu}$ $\mathrm{K} \alpha=1.54 \AA$ and a step scan of 0.02 degree at room temperature. Bragg's law defined as $\lambda=2 d \operatorname{Sinq}$ was used to compute the crystallographic spacing $(d)$ for unmodified and organically modified clay. FTIR spectra were performed using a Bruker spectrometer model vector 22 , in transmittance mode and with a resolution of $4 \mathrm{~cm}^{-1}$.

\section{Composite preparation}

$\mathrm{PP} /$ filler nanocomposites were prepared in two stages. In the first stage a masterbatch was prepared by melt mixing of filler with the compatibilizer (PP-g-MA) (Polybond 3200) in a 1:3 weight ratio in a Brabender at $190^{\circ} \mathrm{C}$, 
$75 \mathrm{rpm}$, during 10 minutes and under a nitrogen flow to avoid oxidation. The nanocomposites with different filler contents were then obtained by diluting a known amount of the masterbatch in a determined amount of PP by melt mixing under the same conditions as those used for the preparation of the masterbatch. In this way PP/oMMT nanocomposites were prepared at 3 wt. $\%, 5$ wt. $\%$ or 7 wt. $\%$ filler, while $\mathrm{PP} / \mathrm{CC}$ and $\mathrm{PP} / \mathrm{MCC}$ composites were prepared by a one step process through melt mixing of filler with PP at $15 \mathrm{wt}$. $\%, 30$ wt. $\%$ or 40 wt. $\%$ of the filler.
$\mathrm{PP} / \mathrm{oMMT} / \mathrm{CC}$ and PP/oMMT/MCC hybrid nanocomposites were obtained by two stages. In the first stage a masterbatch consisting of a mixture of oMMT/Polybond with mass ratio of 1:3 and neat PP was prepared. In the second stage $\mathrm{CC}$ or MCC filler was added to this mixture. These hybrid composites contained either 3 wt. $\%, 5$ wt. $\%$ or 7 wt. $\%$ of oMMT and 30 wt. $\%$ of CC or MCC. The compositions of the prepared nanocomposites are summarized in Table 1.

Table 1 Composition of prepared PP/oMMT nanocomposites, PP/oMMT/CC and PP/oMMT/MCC hybrid nanocomposites.

\begin{tabular}{|c|c|c|c|c|c|}
\hline \multirow{2}{*}{ Composite } & \multirow{2}{*}{$\begin{array}{l}\text { Matrix } \\
\text { PP }\end{array}$} & \multirow{2}{*}{$\begin{array}{l}\text { Compatibilizer } \\
\text { Polybond } 3002\end{array}$} & \multicolumn{3}{|c|}{ Filler } \\
\hline & & & oMMT & $\mathrm{CC}$ & MCC \\
\hline & (wt. \%) & (wt. \%) & (wt. \%) & (wt. \%) & (wt. \%) \\
\hline PP & 100 & & & & \\
\hline PP/Polybond (9\%) & 91 & 9 & & & \\
\hline PP/Polybond (15\%) & 85 & 15 & & & \\
\hline PP/Polybond (21\%) & 79 & 21 & & & \\
\hline PP/oMMT (3\%) & 88 & 9 & 3 & & \\
\hline PP/oMMT (5\%) & 80 & 15 & 5 & & \\
\hline PP/oMMT (7\%) & 72 & 21 & 7 & & \\
\hline $\mathrm{PP} / \mathrm{CC}(15 \%)$ & 85 & & & 15 & \\
\hline $\mathrm{PP} / \mathrm{CC}(30 \%)$ & 70 & & & 30 & \\
\hline $\mathrm{PP} / \mathrm{CC}(40 \%)$ & 60 & & & 40 & \\
\hline $\mathrm{PP} / \mathrm{MCC}(15 \%)$ & 85 & & & & 15 \\
\hline $\mathrm{PP} / \mathrm{MCC}(30 \%)$ & 70 & & & & 30 \\
\hline $\mathrm{PP} / \mathrm{MCC}(40 \%)$ & 60 & & & & 40 \\
\hline PP/oMMT (3\%)/CC (30\%) & 58 & 9 & 3 & 30 & \\
\hline PP/oMMT (5\%)/CC (30\%) & 50 & 15 & 5 & 30 & \\
\hline PP/oMMT (7\%)/CC (30\%) & 42 & 21 & 7 & 30 & \\
\hline PP/oMMT (3\%)/MCC (30\%) & 58 & 9 & 3 & & 30 \\
\hline PP/oMMT (5\%)/MCC (30\%) & 50 & 15 & 5 & & 30 \\
\hline P/oMMT (7\%)/MCC (30\%) & 42 & 21 & 7 & & 30 \\
\hline
\end{tabular}

These composites were characterized by tensile mechanical measurements using a dynamometer HP industries, Buenos Aires, Argentina model D500 at a rate of $50 \mathrm{~mm} / \mathrm{min}$ at $23{ }^{\circ} \mathrm{C}$ and $30 \%$ relative humidity and by thermogravimetric analysis (TGA) by using a TA instrument model SDT2960 simultaneous DSCTGA thermal analyzer. The morphology of the composites was studied by wide-angle X-ray diffraction (XRD) and scanning electron microscopy (SEM). XRD patterns were obtained by using a Siemens model D-5000 powder $\mathrm{X}$-ray diffractometer (Munich, Germany) with $\mathrm{Cu} \mathrm{K} \alpha=1.54 \AA$ and a step scan of 0.02 degree at room temperature. SEM images of the composites were obtained by using a Philips XL 30 ESEM scanning electron microscope.

\section{RESULTS AND DISCUSSION}

\section{$X$-ray diffraction and FTIR analyses}

$\mathrm{X}$-ray diffraction pattern of the organoclay powder (oMMT) is shown in Figure 1. The diffraction peak at $2 \theta=2.88$ degrees corresponds to a basal spacing $\left(\mathrm{d}_{001}\right)$ of $3.07 \mathrm{~nm}$, much higher tan $1.26 \mathrm{~nm}$ of the pristine sodiumMMT clay. The enlarged interlayer space of the organoclay, due to intercalation of the alkyl ammonium surfactant (DSQ), indicates the decrease of electrostatic interaction between adjacent clay layers and provides a good opportunity for macromolecular chains to diffuse into the interlayer space of the clay during melt compounding. Furthermore, pristine MMT and oMMT were analyzed by FTIR spectroscopy (Figure 2). As seen in Figure 2(b), oMMT shows two new absorption bands at $2920 \mathrm{~cm}^{-1}$ and $2850 \mathrm{~cm}^{-1}$ corresponding to the stretching vibration of $\mathrm{C}-\mathrm{H}$ bonds of aliphatic chains of organic modifier confirming the successful intercalation of DSQ in the clay layers. These absorption bands are absent in the FTIR spectrum of pristine MMT as seen in Figure 2(a).

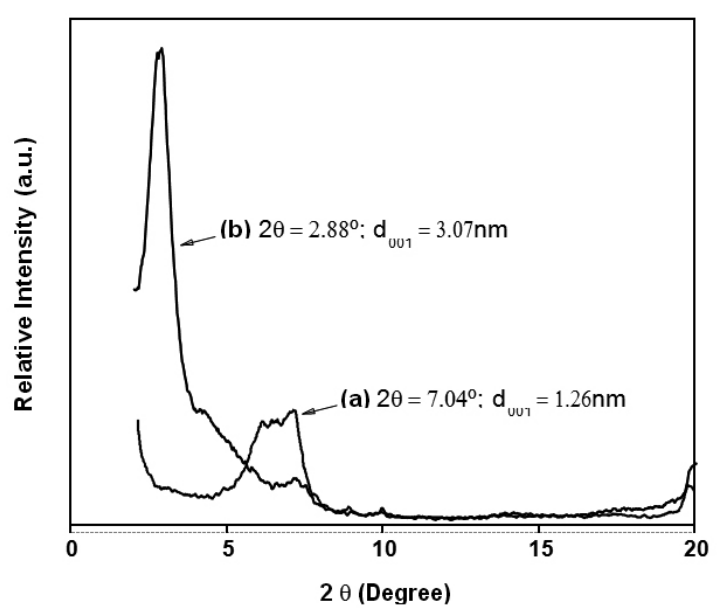

Fig. 1. XRD patterns of MMT (a) and oMMT (b). 


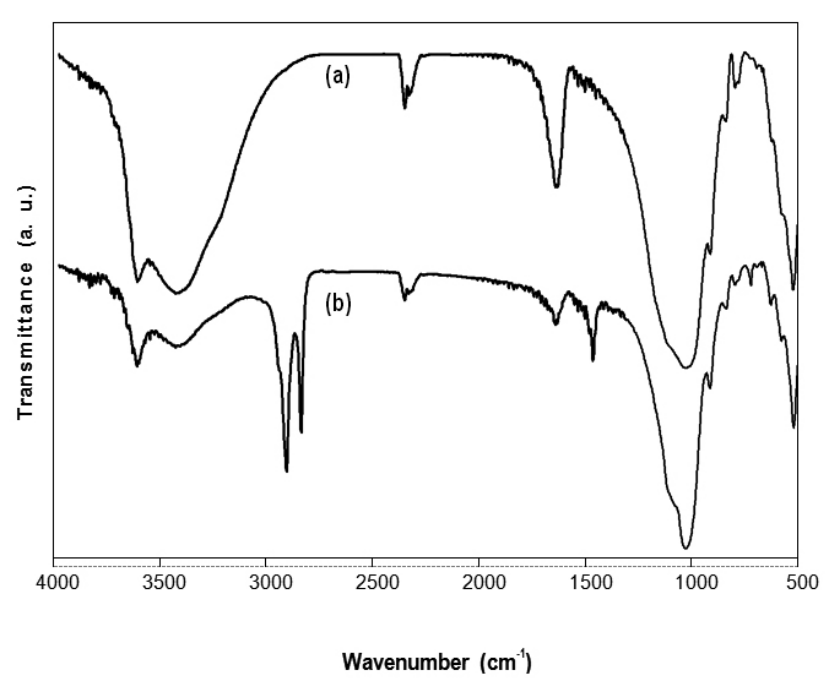

Fig. 2. FTIR spectra of MMT (a) and oMMT (b).

Figure 3 shows the XRD patterns of $\mathrm{PP} / \mathrm{CC}$, PP/MCC composites and hybrid nanocomposites prepared in this study. The characteristic diffraction peak of the organoclay is shifted to lower $2 \theta$ angles and with less intensity for all studied nanocomposites, indicating an increase of the clay basal spacing. This increase is indicative that polymer chains are partially intercalated in the clay galleries. However, the presence of a broad peak for hybrid composite suggests a coexistence of an intercalated and exfoliated structure. This result could be due to the fact that the organoclay is exfoliated and dispersed in the matrix during the melt compounding. However, the PP/oMMT composite shows a typical diffraction peak corresponding to the modified organoclay in this composite. According to these results it can be concluded that the XRD analysis is a reliable tool for analyzing the complex dispersion of clay layers in hybrid nanocomposites, particularly, $\mathrm{PP} / \mathrm{oMMT} / \mathrm{CaCO}_{3}$ clay systems, where the location of clay determines the exfoliation or intercalation phenomenon. Furthermore, it can observed from XRD analysis that the interlaminar distance of the clays in the PP/CC, PP/MCC composites and hybrid nanocomposites is larger than the hybrid clay, indicating the conservation of the crystallinity of these materials and that the morphology of these composites could be considered as exfoliated or intercalated (Table 2). The appearance of a diffraction peak at angle $2 \theta=5$ degrees could be associated with the fact that intercalation could occur in other layers than $\mathrm{d}_{001}$ layer resulting in a more symmetric intercalation.

Table 2: XRD data of montmorillonite (MMT), organically modified MMT(oMMT), PP/oMMT nanocomposite, PP/oMMT/CC and PP/oMMT/ MCC hybrid nanocomposites.

\begin{tabular}{|l|c|c|}
\hline Sample & $\begin{array}{c}2 \theta \\
(\text { Degree })\end{array}$ & $\begin{array}{c}\text { Interlayer distance } \\
(\mathrm{d} 001)(\mathrm{nm})\end{array}$ \\
\hline MMT & 7.04 & 1.26 \\
\hline oMMT & 2.88 & 3.07 \\
\hline PP/oMMT (7\%) & 2.30 & 3.84 \\
\hline PP/oMMT (7\%)/CC (30\%) & 2.30 & 3.84 \\
\hline PP/oMMT (7\%)/MCC (30\%) & 2.32 & 3.81 \\
\hline
\end{tabular}

\section{Tensile mechanical properties}

In general, the composition of polymeric composites has great effect on the properties of these materials, especially on their tensile behaviour [17-23]. In this study binary $\mathrm{PP} / \mathrm{oMMT}$ and $\mathrm{PP} / \mathrm{CaCO}_{3}$ composites were prepared. The enhancement of the mechanical properties observed for these composites could be related with the amount and type of the filler used. To further enhance the mechanical properties of $\mathrm{PP}$ composites, $\mathrm{PP} / \mathrm{oMMT} / \mathrm{CaCO}_{3}$ hybrid composites with different compositions were prepared.
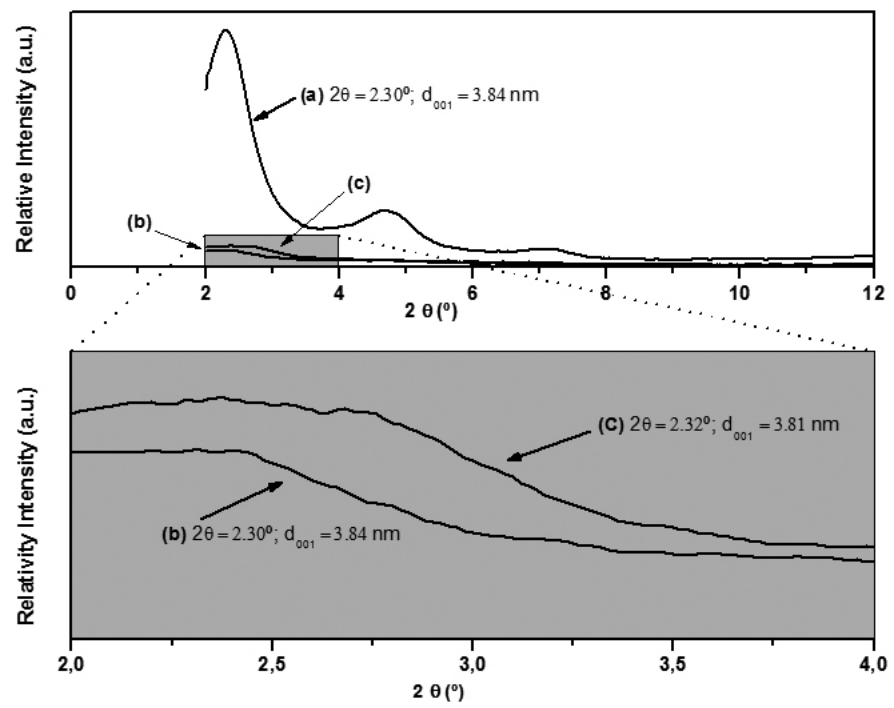

Fig. 3. XRD patterns of PP/oMMT (7 wt. \%) nanocomposite (a), PP/ oMMT (7 wt. \%)/CC (30 wt. \%) hybrid composite (b) and PP/oMMT (7 wt. $\%) / \mathrm{MCC}(30$ wt. \%)/PP hybrid composite (c).

\section{PP/oMMT nanocomposites}

Compared with the neat PP, the yield stress and tensile modulus of PP/ oMMT composites were improved in the range of $10-20 \%$ and $30-50 \%$, respectively (Table 3 ). This is due to the higher rigidity and higher modulus of the oMMT than that of the PP matrix. The elongation at break decreases slightly with increasing the content of oMMT from 3 to 7 wt. \%. The normalized Young modulus $\left(E^{*}\right)$, that is, the ratio of composite's modulus to that of the neat PP, are shown in Figure 4. Values of $E^{*}$ in the range of 1.30 to $1.50 \mathrm{MPa}$ confirm this enhancement of composites modulus related to neat PP. Differing from PP/CC or PP/MCC, in PP/oMMT composites the yield stress was increased considerably. This suggests an improved and good interfacial interaction between the clay and PP matrix. The improved interfacial interaction should be benefited from the use of Polybond as compatibilizer.

\section{$\mathrm{PP} / \mathrm{CaCO}_{3}$ composites}

The experimental conditions for $\mathrm{PP} / \mathrm{CaCO}_{3}$ composites, including content, origin and morphology of $\mathrm{CaCO}_{3}$ filler were also optimized. In this case PP/CC and PP/MCC microcomposites with 15,30 or 40 wt. \% filler content were prepared and their mechanical properties were determined (Table $3)$.

The results show that the tensile modulus increased while the yield stress and the elongation at break decreased as the filler content increased (Table 3). The maximum value of modulus was

$1.85 \mathrm{GPa}$ when the filler content was 40 wt. \%. Compared with the neat $\mathrm{PP}$, the tensile modulus of $\mathrm{PP} / \mathrm{CaCO}_{3}$ composites was increased from $20 \%$ to $60 \%$ by using $15 \mathrm{wt}$. $\%$ to $40 \mathrm{wt}$. \% of CC or MCC as filler, respectively. In the case of yield stress, a slight decrease occurred at a high filler loading. This phenomenon can be attributed to the nucleation effect of the $\mathrm{CaCO}_{3}$ particles and the weak interfacial interactions between the $\mathrm{CaCO}_{3}$ particles and the PP matrix. The latter made it possible for the occurrence of debonding at the particle/matrix boundary before yielding [24]. In fact, for PP/CC or PP/ MCC composites, the value are in the range of 27 - $30 \mathrm{MPa}$ compared with 32 MPa for neat PP. The elongations at break of these composites are $2.4 \%$ to $5.3 \%$ compared with $8.5 \%$ of neat PP. The mechanical behaviour of these PP composites no exhibited any significant difference between the two types of $\mathrm{CaCO}_{3}$ filler used, namely, the $\mathrm{CC}$ and MCC. However, the microstructure of the $\mathrm{PP} / \mathrm{CC}$ composites shows more microvoids than the $\mathrm{PP} / \mathrm{MCC}$ composites (see Figure $4 \mathrm{c}$ and $4 \mathrm{~d}$ ). These results are in agreement with those obtained in our previous study concerning the use of $\mathrm{CaCO}_{3}$ and talc as fillers for PP [25]. 
Table 3 Tensile mechanical properties of PP, PP/clay nanocomposites, PP/oMMT/CC and PP/oMMT/MCC hybrid nanocomposites.

\begin{tabular}{|l|c|c|c|}
\hline Composite & $\begin{array}{c}\text { Tensile modulus } \\
(\mathrm{GPa})\end{array}$ & $\begin{array}{c}\text { Maximum stress } \\
(\mathrm{MPa})\end{array}$ & $\begin{array}{c}\text { Elongation at break } \\
(\%)\end{array}$ \\
\hline PP & $1.17 \pm 0.06$ & $32.0 \pm 0.4$ & $8.5 \pm 0.1$ \\
\hline PP/Polybond (9\%) & $1.48 \pm 0.06$ & $37.0 \pm 1.3$ & $7.8 \pm 0.3$ \\
\hline PP/Polybond (15\%) & $1.48 \pm 0.03$ & $38.0 \pm 1.1$ & $7.5 \pm 1.0$ \\
\hline PP/Polybond (21\%) & $1.56 \pm 0.03$ & $40.0 \pm 0.5$ & $7.1 \pm 0.1$ \\
\hline PP/oMMT (3\%) & $1.58 \pm 0.05$ & $36.0 \pm 1.5$ & $6.2 \pm 0.8$ \\
\hline PP/oMMT (5\%) & $1.67 \pm 0.04$ & $38.0 \pm 0.7$ & $6.4 \pm 0.8$ \\
\hline PP/oMMT (7\%) & $1.76 \pm 0.07$ & $37.0 \pm 0.9$ & $5.3 \pm 0.6$ \\
\hline PP/CC (15\%) & $1.44 \pm 0.01$ & $31.0 \pm 0.3$ & $6.0 \pm 0.3$ \\
\hline PP/CC (30\%) & $1.68 \pm 0.12$ & $27.0 \pm 0.4$ & $3.5 \pm 0.1$ \\
\hline PP/CC (40\%) & $1.85 \pm 0.09$ & $26.0 \pm 0.5$ & $2.4 \pm 0.1$ \\
\hline PP/MCC (15\%) & $1.43 \pm 0.04$ & $30.0 \pm 0.4$ & $5.3 \pm 0.2$ \\
\hline PP/MCC (30\%) & $1.70 \pm 0.03$ & $28.0 \pm 1.4$ & $3.1 \pm 0.2$ \\
\hline PP/MCC (40\%) & $1.80 \pm 0.07$ & $27.0 \pm 0.6$ & $2.5 \pm 0.3$ \\
\hline PP/oMMT (3\%)/CC (30\%) & $1.66 \pm 0.06$ & $30.0 \pm 0.9$ & $2.9 \pm 0.4$ \\
\hline PP/oMMT (5\%)/CC (30\%) & $1.74 \pm 0.06$ & $32.0 \pm 2.2$ & $3.8 \pm 0.4$ \\
\hline PP/oMMT (7\%)/CC (30\%) & $1.85 \pm 0.09$ & $27.0 \pm 1.0$ & $2.4 \pm 0.4$ \\
\hline PP/oMMT (3\%)/MCC (30\%) & $1.85 \pm 0.04$ & $34.0 \pm 1.4$ & $3.5 \pm 0.4$ \\
\hline PP/oMMT (5\%)/MCC (30\%) & $1.85 \pm 0.01$ & $33.0 \pm 4.2$ & $3.6 \pm 1.3$ \\
\hline PP/oMMT (7\%)/MCC (30\%) & $1.95 \pm 0.10$ & $35.0 \pm 0.3$ & $3.1 \pm 0.1$ \\
\hline
\end{tabular}

On the basis of the above results, we chose an optimal filler concentration of 30 wt. \% of either CC or MCC for the elaboration of PP composites (Table 3 ). This filler concentration produced composites with improved tensile modulus and strength while the elongation at break remained unaltered. This is in accordance with the observed morphology for these composites, where the interfacial interaction between the filler and PP matrix is optimal. That is, the external load was transferred to the filler through the interface and high strength filler bear the main load improving the mechanical modulus of these composites [25].

\section{PP/oMMT/CaCO3 hybrid composites}

As shown in Table 3, compared with that of the $\mathrm{PP} / \mathrm{CaCO}_{3}$ systems, the mechanical properties of hybrid composites were slightly improved. That is, the toughness of the PP/oMMT was sensibly increased by the addition of $\mathrm{CaCO}_{3}$ filler. This could be attributed to a synergistic effect when a combination of nano-clay and $\mathrm{CaCO}_{3}$ were used as fillers. The tensile modulus and maximum stress of hybrid composites increases while the elongation at break decreases with the oMMT content. Compared with the $\mathrm{PP} / \mathrm{CaCO}_{3}$ the tensile modulus increases by $10-15 \%$ for $30 \mathrm{wt}$. \% of CC or MCC and the maximum stress in about $18-25 \%$. However the hybrid composites increase the tensile modulus in about $10-17 \%$ compared with the PP/oMMT composites and the maximum stress show a slight decrease with the oMMT content. In the hybrid composites, the yield stress was almost the same as that in $\mathrm{PP} /$ oMMT composites, although a slight increase was observed. This comparable yield stress between hybrid and $\mathrm{PP} / \mathrm{CaCO}_{3}$ composites was believed to be the result of two counterbalance effects associated with the addition of $\mathrm{CaCO}_{3}$ in PP/oMMT composites. One was the enhanced exfoliation extent, leading to a higher yield stress, and the other was the detrimental effect of the $\mathrm{CaCO}_{3}$ particles on the yield stress.

An interesting fact is the effect of the type of the calcium carbonate on tensile properties of these hybrid composites. A significant enhancement of the mechanical properties was observed when MCC filler with lager particle size $(8.4 \mu \mathrm{m})$ than $\mathrm{CC}(0.7 \mu \mathrm{m})$ and a specific surface area $\left(18.0 \mathrm{~m}^{2} / \mathrm{g}\right)$ higher than CC $(9.1 \mathrm{~m} / \mathrm{g})$ was used. The tensile modulus of PP/oMMT/MCC composites were found to be in the range of 1.85-1.95 GPa while lower values from 1.66 GPa to

$1.85 \mathrm{GPa}$ were found for hybrid composites with $\mathrm{CC}$ as filler compared to $1.17 \mathrm{GPa}$ for neat PP. Furthermore, the yield stress for the hybrid composites with MCC microfiller was found to be in the range of 33 to $35 \mathrm{MPa}$ compared with lower values observed for the CC microfiller (27-32 MPa) and comparing with that of neat PP $(32 \mathrm{MPa})$. This means that MCC is the most effective reinforcing filler for elaboration of PP-clay hybrid nanocomposites. The difference in performance observed for $\mathrm{CC}$ and MCC could be attributed to different morphology of these fillers as seen from SEM micrographs of Figure $6 \mathrm{c}$ and $\mathrm{d}$. It is suggested that due to the morphology and organophilic character of MCC, this filler has better interfacial interactions with PP as compared with CC. This allows the external force to be transferred easily to MCC particles. Rigid MCC particles absorb part of the impact energy and therefore the crack propagation effect produced by the shock could be reduced [26].

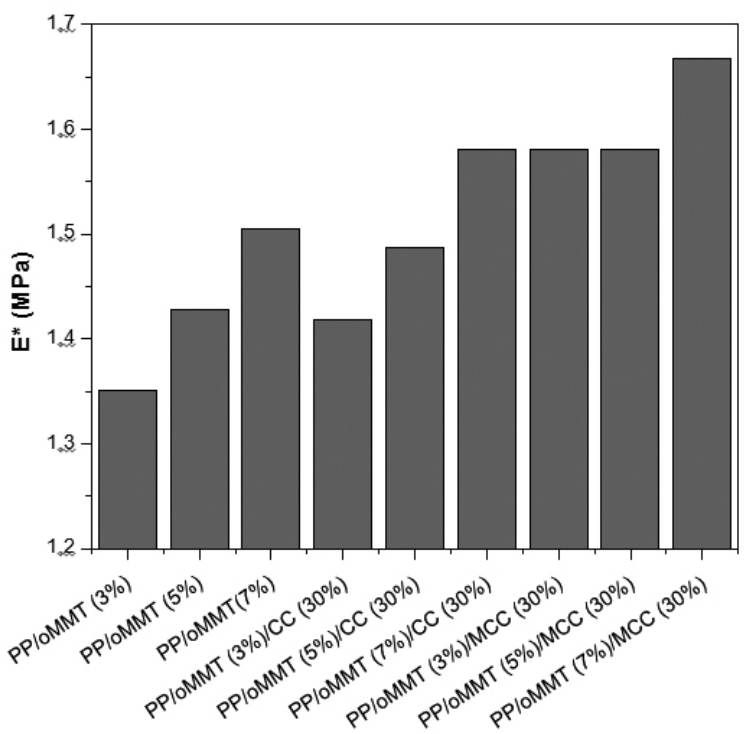

Fig. 4. Normalized Young modulus $\left(E^{*}\right)$ of nanocomposites and hybrid nanocomposites. 


\section{Thermal properties}

Thermogravimetric analysis (TGA) was used to study the thermal stability of the nanocomposites. Figure 5 shows the weight loss temperature curves (TG) and the first derivative of TG curves (DTG) of PP, PP/oMMT nanocomposites and hybrid nanocomposites containing either CC or MCC. The peak degradation temperature and the weight loss rate can be estimated from DTG curves. This peak degradation temperature (DTG peak) corresponds to the weight loss rate where the maximum degradation occurs. Furthermore, the mass loss percentage is obtained from the TGA curve at the DTG peak. The results obtained for PP, PP/oMMT nanocomposite and hybrid nanocomposites are presented in Table 4. According to the thermal behavior observed for these nanocomposites the decomposition mechanism could be attributed principally to the functionalization process of PP occurring in one step located around $400-550^{\circ} \mathrm{C}$. The polar organic compound present in Polybond and the oMMT could be the principal decomposition events to explain the thermal stability of nanocomposites. In the case of PP the thermal degradation is known to occur principally by a random scission mechanism [27].

Table 4 Thermal properties of PP, PP/oMMT nanocomposites, PP/ oMMT/CC and PP/oMMT/MCC hybrid nanocomposites.

\begin{tabular}{|l|c|c|c|}
\hline \multicolumn{1}{|c|}{ Composite } & $\begin{array}{c}\text { DTG peak } \\
\text { Tempertature } \\
\left({ }^{\circ} \mathbf{C}\right)\end{array}$ & $\begin{array}{c}\text { DTG } \\
\text { value } \\
(\% / m i n)\end{array}$ & $\begin{array}{c}\text { Weight } \\
\text { Loss } \\
(\%)\end{array}$ \\
\hline PP & 470 & -49.5 & 58.2 \\
\hline PP/oMMT (7\%) & 467 & -185.5 & 70.3 \\
\hline PP/oMMT (7\%)/CC (30\%) & 468 & -106.2 & 51.8 \\
\hline PP/oMMT(7\%)/MCC (30\%) & 482 & -45.6 & 50.4 \\
\hline
\end{tabular}

From the results summarized in Table 4, it can be observed that the PP/ oMMT/MCC hybrid nanocomposite is the material thermally more stable with an increase of about $15{ }^{\circ} \mathrm{C}$ with PP/oMMT nanocomposite. In addition, the weight loss rate at peak degradation temperature of this hybrid composite exhibit a slight decrease as compared with the neat PP (-45.6 to $-49.5 \%$ / $\mathrm{min})$ but it is lower than other composites $(-185.5 \% / \mathrm{min}$ for binary PP/ oMMT and $106.2 \% / \mathrm{min}$ for $\mathrm{PP} / \mathrm{oMMT} / \mathrm{CC}$ composite) occurring at higher peak degradation temperature $\left(482^{\circ} \mathrm{C}\right)$ than $\mathrm{PP}$ and other composites.
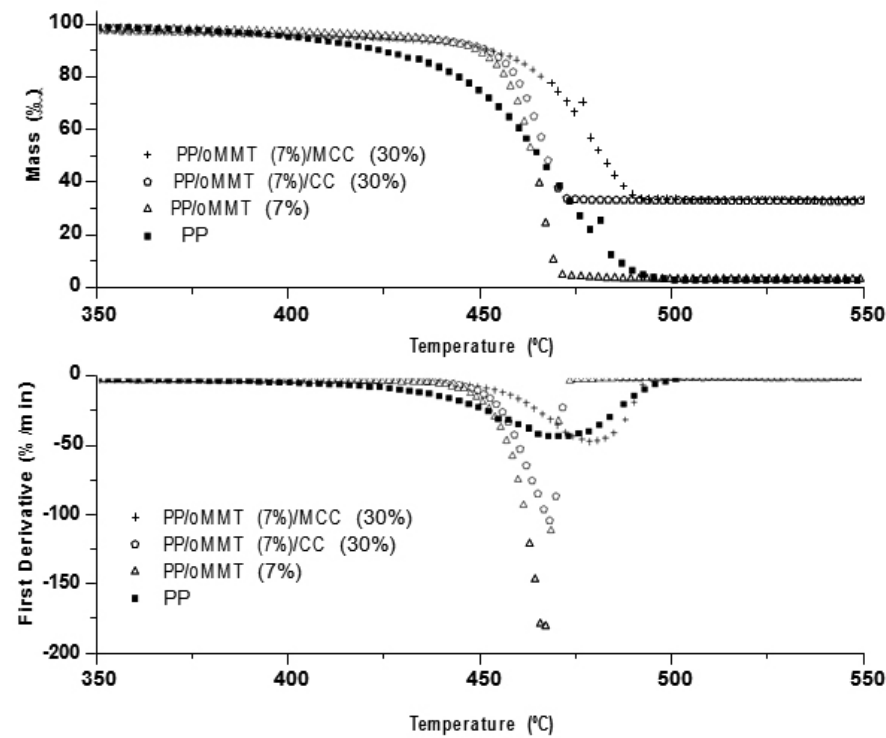

Fig. 5. Thermogravimetric analysis of selected $P P$ nanocomposites and $P P$ hybrid nanocomposites. TGA curves (a) and DTG curves (b).

The higher thermal stability of the PP/oMMT/MCC hybrid composite could be attributed to two phenomena: the partial exfoliation of the clay in the PP matrix that restricts the diffusion of volatiles from the bulk known as labyrinth effect and to the MCC morphology by comparing the specific area $\left(18 \mathrm{~m}^{2} / \mathrm{g}\right)$ and pore diameter $(114 \AA)$ of MCC with those of CC $\left(9.1 \mathrm{~m}^{2} / \mathrm{g}\right.$ and $124 \AA$ ). Additionally, the observed lower thermal stability of the PP/o-MMT composites compared with the PP/o-MMT composites containing CC or MCC as second filler could be explained by considering that MCC could confine the organic radicals released by thermal degradation more easily than $\mathrm{CC}$ and that these radicals could participate in partial crosslinking of PP chains resulting in a more thermally stable material $[28,29]$.

\section{Morphological analysis}

To ensure the increase of toughness by adding $\mathrm{CaCO}_{3}$ filler, namely $\mathrm{CC}$ or MCC particles, to PP/oMMT composites (Table 3), we studied the morphology of tensile fracture section, which was closely related with the fracture mode. There are two fracture modes in polymer composites: ductile fracture and brittle fracture. In the ductile fracture, the matrix dissipates the energy via shear yielding and crazes expansion, while in the brittle fracture the matrix absorbs the energy via cracks caused by defects and voids of composites [30,31]. The morphologies of fracture section in neat PP and PP/oMMT composite are shown in Figure $6 \mathrm{a}$ and $6 \mathrm{~b}$. The neat PP belongs to a typical brittle fracture, where the fracture section was flat. However, the fracture section of PP/oMMT composite became uneven, indicating that some degree of ductile fracture phenomenon occurred. As shown in Figure $6 \mathrm{c}$ or $6 \mathrm{~d}$, there is an obvious gap between $\mathrm{CaCO}_{3}$ particles, either $\mathrm{CC}$ or $\mathrm{MCC}$, and PP matrix. This was mainly attributed to the addition of $\mathrm{CaCO}_{3}$ filler to polymer composites, resulting in an increase of the interfacial interaction and compatibility between MCC and PP matrix as compared with CC. This is because the higher aspect ratio of MCC than CC particles, as shown Figure 7 , prompts better dispersion of the MCC than CC in PP matrix. Thus the mechanical properties of PP/oMMT/MCC hybrid composite were improved (Table 3).
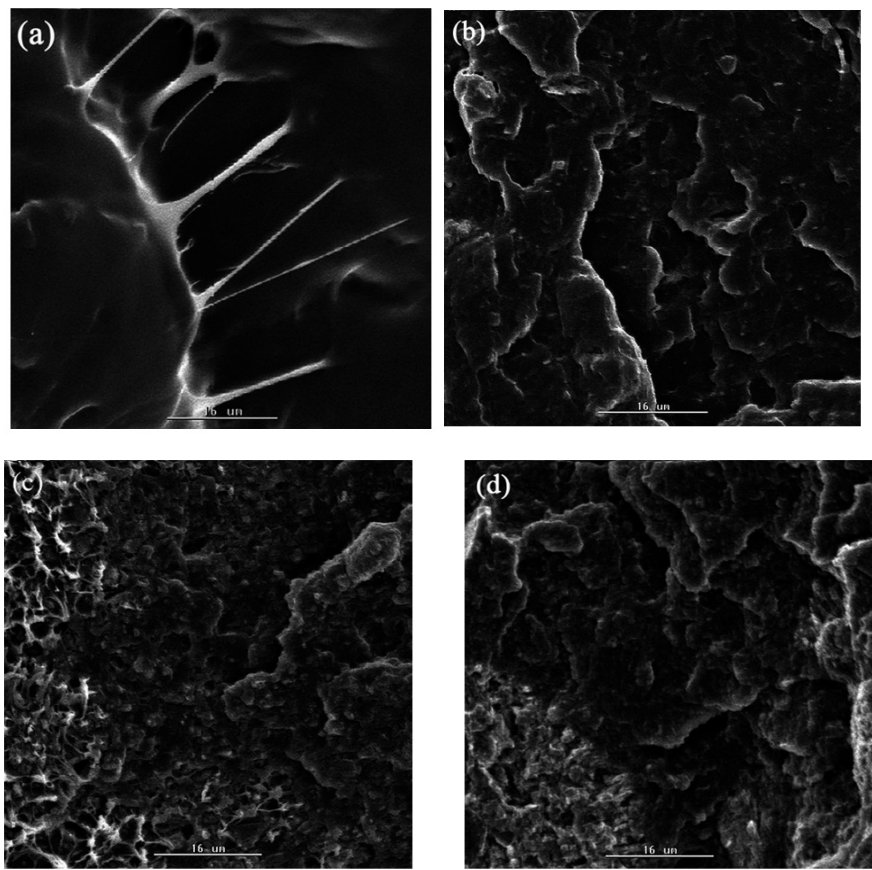

Fig. 6. SEM micrographs taken from fracture surfaces of neat PP (a), PP/ oMMT (7 wt. \%) nanocomposite (b), PP/oMMT (7 wt. \%)/CC (30 wt. \%) hybrid nanocomposite (c) and PP/oMMT (7 wt.\%)/MCC (30 wt. \%) hybrid nanocomposite (d). 

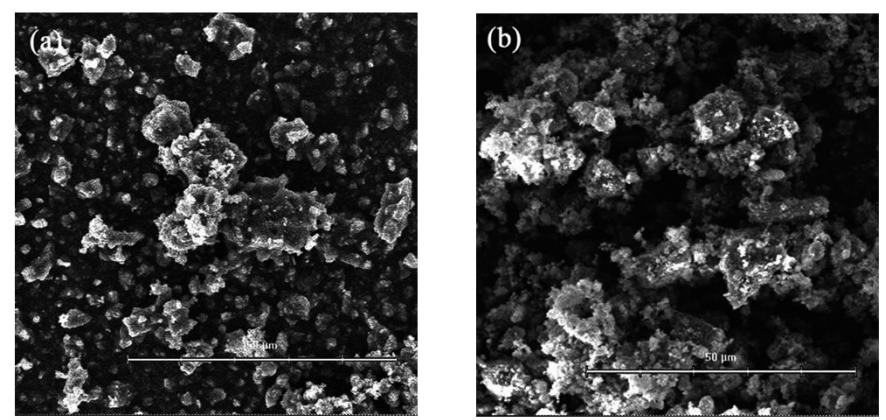

Fig. 7. SEM micrographs of different calcium carbonate fillers. CC (a) and $\mathrm{MCC}(\mathrm{b})$.

\section{CONCLUSIONS}

$\mathrm{PP} / \mathrm{CaCO}_{3}$ and hybrid PP-based nanocomposites with organically modified montmorillonite (oMMT) and different types of $\mathrm{CaCO}_{3}$ particles were prepared via melt blending. A synergic effect between fillers was observed in particular when biomineralized calcium carbonate (MCC) was used. With the addition of MCC particles to PP/oMMT composite, the exfoliation extent of the clay was substantially enhanced compared with the commercial $\mathrm{CaCO}_{3}$ filler. Much higher tensile modulus, yield stresses and thermal stability were thereby resulted. The reinforcing mechanism was mainly due to the synergistic effect of oMMT and $\mathrm{CaCO}_{3}$, especially in the presence of biomineralized $\mathrm{CaCO}_{3}$ with higher surface area and lower pore size than commercial $\mathrm{CaCO}_{3}$ particles. Our study may help to design and development of high performance PP composites.

\section{ACKNOWLEDGMENTS}

Financial support of Conicyt through Project FONDECYT 1131139 is acknowledged. H. Aguilar is thankful to the Conicyt for a doctorate scholarship.

\section{REFERENCES}

1. K.Y. Rhee, S.G. Lee, J.H. Lee, Mater. Sci. Technol. 21, 743 (2005)

2. K. Palanikumar, J.P. Davim, J. Mater. Process. Technol. 209, 511 (2009)

3. J. Ganster, H.P. Fink, M. Pinnow, Composites, Part A 37, 1796 (2006)

4. T. Paunikallio, J. Kasanen, M. Suvanto, T.T. Pakkanen, J. Appl. Polym. Sci. 87, 1895 (2003)
5. P.B. Leng, H.M. Akil, O.H. Lin, J. Reinf. Plast. Compos. 26, 761 (2007) 6. J. Gu, D.S. Jia, R.S.Cheng, Polym. Plast. Technol. Eng. 47, 583 (2008)

7. Y.H. Cui, X. Jin, F. Shen, C. Han, J.B.Wang, J. Vinyl. Addit. Technol. 15, 178 (2009) [8] M. Sarkar, K. Dana, S. Ghatak, A. Banerjee, Bull. Mater. Sci. 31, 23 (2008)

8. W.H. Li, X.H. Chen, Z. Yang, L.S.Xu, J. Appl. Polym. Sci. 113, 3809 (2009)

9. M.A. Lopez-Manchado, L. Valentini, J. Biagiotti, J.M.Kenny, Carrbon 43, 1499 (2005)

10. K. Prakashan, A.K. Gupta, S.N..Maiti, J. Appl. Polym. Sci. 110, 1457 (2008)

11. Y. Ruksakulpiwat, J. Sridee, N. Suppakarn, W. Sutapun, Composites Part B 40, 619 (2009)

12. H. Joshi, J. Purnima, Mater. Sci. Eng. A 527, 1946 (2010)

13. D.P.N. Vlasveld, H.E.N. Bersee, S.J. Picken, Polymer 46, 10269 (2005)

14. J. Jancar, A.T. Dibenedetto, J. Mater. Sci. 30, 2438 (1995)

15. J.L. Arias, R. Quijada, P. Toro, M. Yazdani-Pedram, U.S. Patent 007459492B2, December 2, 2008.

16. J.L.Thomason, Composites, Part A 33, 1641 (2002)

17. B.F. Abu-Sharkh, R. Kahraman, S.H. Abbasi, I.A. Hussein, J. Appl. Polym. Sci. 92, 2581 (2004)

18. J.P. Kim, T.H. Yoon, S.P. Mun, J.M. Rhee, J.S. Lee, Bioresour Technol. 97, 494 (2006)

19. M. Abdelmouleh, S. Boufi, M.N. Belgacem, A. Dufresne, Compos. Sci. Technol. 67, 1627 (2007)

20. S.K. Chattopadhyay, R.K. Khandal, R. Uppaluri, A.K. Ghoshal, J. Appl. Polym. Sci. 113, 3750 (2009)

21. A. Ashori, A. Nourbakhsh, Bioresour Technol. 101, 2515 (2010)

22. J.W. Kim, D.G. Lee, J. Nanosci. Nanotechnol. 10, 3650 (2010)

23. W.C.J. Zuiderduin, C. Westzaan, J. Huetink, R.J. Gaymans, Polymer 44, $261(2003)$

24. P. Toro, R. Quijada, M. Yazdani-Pedram, J.L. Arias, Mater. Lett. 61, 4347 (2007)

25. Y.S. Thio, A.S. Argon, R.E. Cohen, M. Weinberg, Polymer 43, 3661 (2002)

26. J. Palacios, R. Perera, C. Rosales, C. Albano, J.M. Pastor, Polym. Degrad. Stab. 97, $729(2012)$

27. T.C. Sun, X. Dong, K. Du, K. Wang, Q. Fu, C.C. Han, Polymer 49, 588 (2008)

28. M.C. Costache, D.D. Jiang, C.A. Wilkie, Polymer. 46, 6947 (2005)

29. F.Y. Ke, X.W. Jiang, H.Y. Xu, J.L. Ji, Y. Su, Compos. Sci. Technol. 72, $574(2012)$

30. H.B. Chen, M.Z. Wang, Y. Lin, C.M. Chan, J.S. Wu, J. Appl. Polym. Sci. 1063409 (2007) 